\title{
THE EFFECT OF CURE CYCLE TIME ON THE PROPERTIES OF EPOXY-BONDED JOINTS
}

\author{
Magdalena Zabłocka ${ }^{1}$ \\ Michal Salaciński ${ }^{1}$ \\ Piotr Synaszko ${ }^{1}$ \\ Sylwester Kłysz ${ }^{1,2}$ \\ ${ }^{1}$ Air Force Institute of Technology, Warsaw \\ ${ }^{2}$ University of Warmia and Mazury, Olsztyn
}

\begin{abstract}
This paper presents the results of the study of the properties of epoxy-bonded joints. Depending on the parameters of cure cycles the epoxy adhesive film has got various mechanical properties. When it is possible to use cure parameters suggested in the data sheet of the adhesive film the best results are obtained. However, in aerospace applications the cure cycle depends on the thermal resistance of other aircraft elements including electrical equipment, cables, etc., and is different from the recommended in the data sheet. Composite Patch Bonded Repair (CPBR) is a special methodology, where the patch cure cycle and the bonding process must be carried out in one operation. The adhesive film cure cycle parameters depend on the prepreg cure cycle parameters.

The purpose of this research is to define the influence of a prolonged cure cycle of the adhesive film on the bonded layer strength properties. The metal surface of the specimen has been prepared for bonding by sandblasting and the use of Corrosion Inhibiting Primer BR 127. The tests were performed with the use of Structural Adhesive Film AF 163-2 and two types of cure cycles: the cycle recommended by the data sheet $-121^{\circ} \mathrm{C} / 60 \mathrm{~min}$ and the prolonged one $-121^{\circ} \mathrm{C} / 105 \mathrm{~min}$.

After the cure cycle the thickness of the bonded layer was measured. Both specimens were comparatively tested during the following strength tests of the bonded layer: static breaking tests using the wedge and the shear strength investigations. The surface of the bonded layer was observed during the tests by an electronic microscope (100x, 200x), which made it possible to demonstrate the effect of the cure cycle on the porosity and observe the nature of the bonded layer damage - de-cohesive and de-adhesive.
\end{abstract}

\section{INTRODUCTION}

Bonded joints fulfill a significant role in the development of new technologies, particularly in the aerospace industry where they give new possibilities of connecting structural elements. With the adhesive connections, the construction size can be reduced and the airframe structure can be simplified. The bonded joints allow for reducing the aircraft operations costs by performing repairs of damaged parts instead of exchanging them. The Composite Patch Bonded Repair (CPBR) is a method that can be used for repairing the metallic and composite structures. The CPBR method includes the following steps: surface preparation prior to bonding, the imposition of Composite Patch, a cure cycle of the composite (prepreg) and the adhesive film, and the final treatment $[1,2]$. The properties of the adhesive film depend on the cure cycle parameters. The best mechanical properties are achieved when the cure cycle is performed in accordance with the material data sheet [1]. However, the CPBR cure cycle of the recovery package - the film adhesive and the prepreg - should be performed in one operation. It is unacceptable to shorten the prepreg heating 
time to make it correspond to the cure cycle of the adhesive layer, since unhardened resin doesn't have desired mechanical properties. It is necessary to prolong the adhesive film cure cycle and perform it in accordance with the recommendations of the prepreg data sheet [2] (Fig. 1).

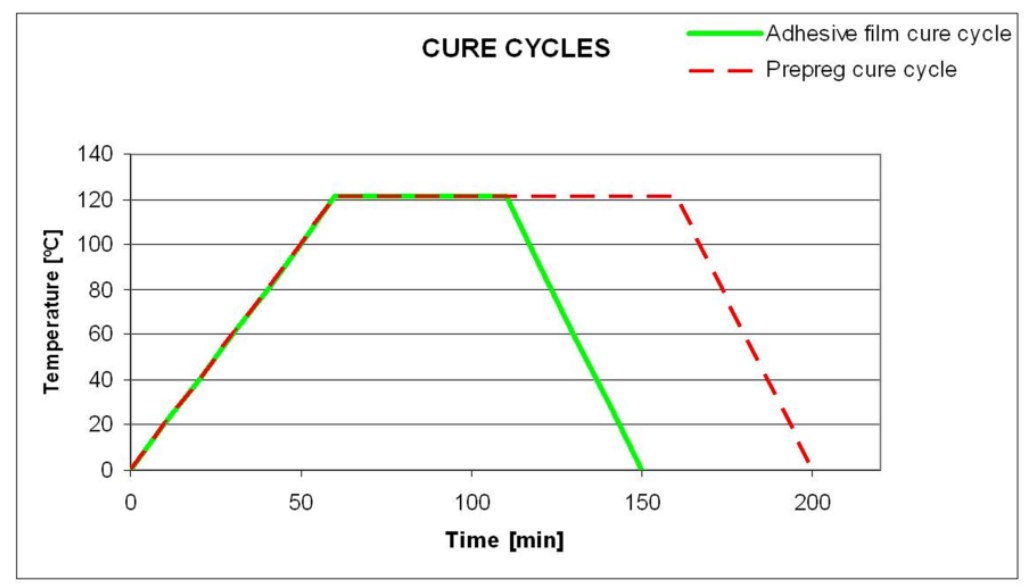

Fig. 1. Matching the cure cycle of the bonded layer to the prepreg required cure cycle

The purpose of the presented research was to determine the effect of prolonged cure cycle time on the mechanical properties of the epoxy bonded layer. The proposed methods were comparative methods. They enabled determination of selected properties of the adhesive film and comparison the results versus the heating time. Additionally, the nature of the bonded layer damage was observed in order to verify whether the surface was properly prepared for bonding.

\section{MANUFACTURING THE SPECIMENS}

For the purpose of research the metal samples in the form of rectangular bars joined by the epoxy bonded layer were prepared. An important factor determining strength of the bonded joint is the process of preparing the surface. In order to prepare the bonded area, the metal surface was subjected to mechanical treatment (sandblasting), which affected the bonded surface as well as the strength of adhesion. To remove impurities the surface was cleaned witch acetone. Next step was to apply the Corrosion Inhibiting Primer to protect bonded layers against corrosion and to increase adhesion [3].

The metal surface prepared according to the above procedure was covered with an adhesive film and with another piece of metal sheet. Two panels were made: the first was subjected to a cure cycle according to adhesive film data sheet - heating in $121^{\circ} \mathrm{C}$ for 60 minutes [4], the second was subjected to a prolonged cure cycle according to the repair prepreg data sheet - heating in $121^{\circ} \mathrm{C}$ for 105 minutes. Subsequently, the samples for testing were cut from these panels.

\section{TESTS RESULTS}

Before performing strength tests the thickness of the bonded layer was measured using an electronic microscope (Tab. 1). It was observed, that the bonded layer subjected to a shorter cure cycle had a larger thickness. This was probably caused by higher porosity as in the heating treatment air is removed slowly - the long heating of the bonded layer enhances removal of gas while the short cure cycle causes more air to stay in the bonded layer. 
Tab. 1. Summary of the measured thicknesses

\begin{tabular}{|l|l|l|}
\hline $\begin{array}{l}\text { Nominal thickness of the adhesive } \\
\text { film in the data sheet }\end{array}$ & $\begin{array}{l}\text { Thickness of the bonded layer - } \\
\text { data sheet cure cycle }(60 \mathrm{~min}) ;\end{array}$ & $\begin{array}{l}\text { Thickness of the bonded layer - } \\
\text { prolonged cure cycle }(105 \mathrm{~min}) ;\end{array}$ \\
\hline $\mathbf{0 . 2 4} \mathbf{~} \mathbf{m m}$ & $\mathbf{0 . 3 1} \mathbf{~} \mathbf{m m}$ & $\mathbf{0 . 2 2} \mathbf{~} \mathbf{m m}$ \\
\hline
\end{tabular}

Both specimens have been tested to determine the forces separating the bonded joint and shear strength of the epoxy bonded layer.

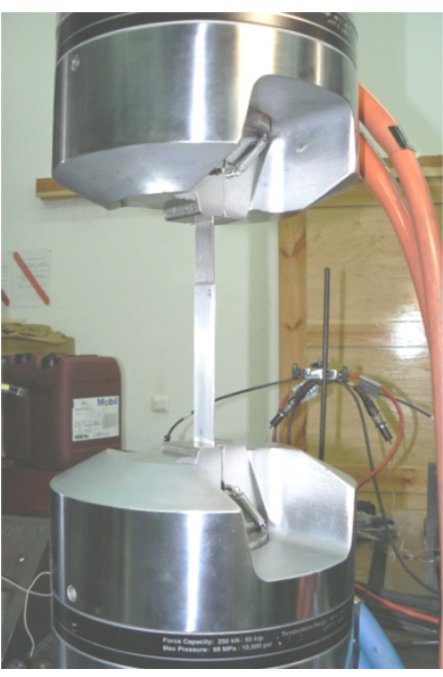

Fig. 2. The wedge test stand with a specimen mounted

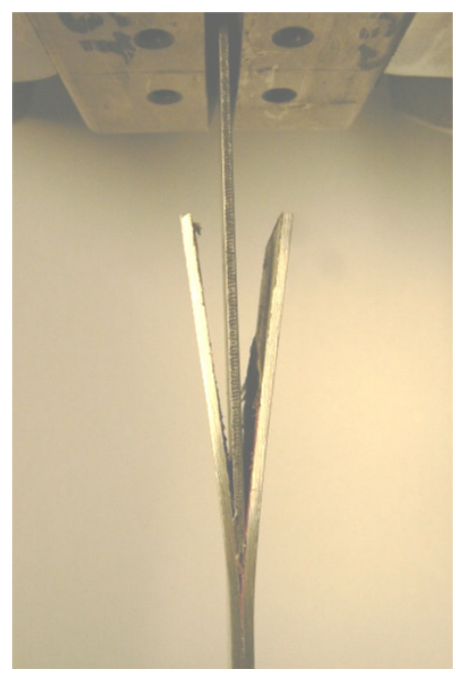

Fig. 3. Specimen during the wedge test

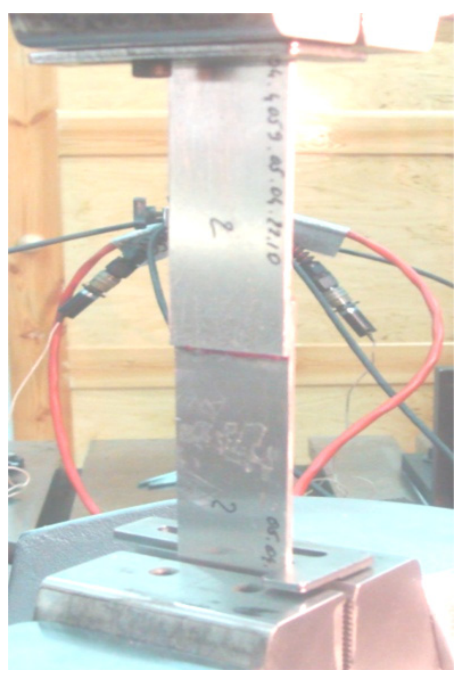

Fig. 4. Specimen during the shear strength test

The wedge tests were performed using the MTS 810.23 testing machine in accordance with ASTM D3762-03 (Fig. 3) at a constant displacement speed of $10 \mathrm{~mm} / \mathrm{min}$.

Following this study, the separation force values were obtained for the tested specimens [6,7]. It was observed that the specimens subjected to the cure cycle according to the data sheet had strength higher by about $10 \%$ (Tab. 2).

Tab. 2. Summary of the values of separating forces for specimens subjected to various cure cycles

\begin{tabular}{|l|l|}
\hline $\begin{array}{l}\text { Average value of maximum separating forces - static } \\
\text { breaking using the wedge, cure cycle } 121^{\circ} \mathrm{C} / 60 \mathrm{~min} .\end{array}$ & $\begin{array}{l}\text { Average value of maximum separating forces - static } \\
\text { breaking using the wedge, cure cycle } 121^{\circ} \mathrm{C} / 105 \mathrm{~min}\end{array}$ \\
\hline $\mathbf{3 7 4} \mathbf{N}$ & $\mathbf{3 3 3} \mathbf{~ N}$ \\
\hline
\end{tabular}

The observation of the specimen's surface by means of an electronic microscope showed that the epoxy bonded layer subjected to a prolonged cure cycle is more homogeneous and has lower porosity (Tab. 3). 
Tab. 3. Comparison of the surfaces of epoxy bonded layers subjected to different cure cycles

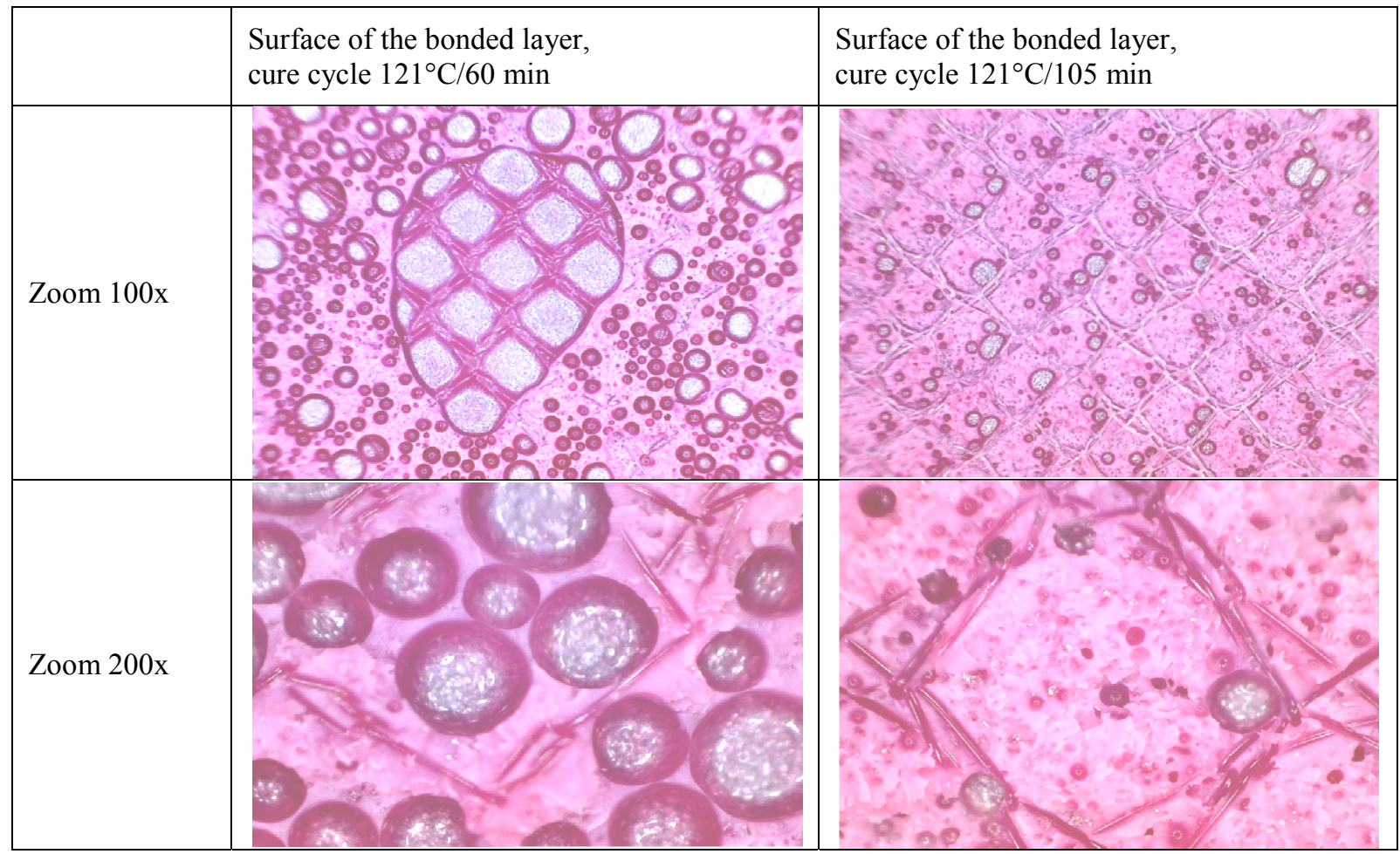

In shear strength tests of the bonded layer, static tensile of specimens with an epoxy bonded layer (Fig. 4) was performed using the MTS 810.23 testing machine at a constant displacement speed of $1.3 \mathrm{~mm} / \mathrm{min}$.

Following this study, the values of shear forces $P_{\max }$ (Tab. 4.) were obtained and the maximum shear stresses $\tau_{\max }$ were determined using the following formula:

$$
\tau_{\max }=\frac{P_{\max }}{A}
$$

where $\mathrm{A}$ is a bonded layer area.

Tab. 4. A comparison of the maximum shear forces and shear strength of the epoxy bonded layer [8,9]

\begin{tabular}{|l|l|l|l|}
\hline $\begin{array}{l}\text { Average shear force - } \\
\text { shear strength test, } \\
\text { cure cycle } 121^{\circ} \mathrm{C} / 60 \mathrm{~min}\end{array}$ & $\begin{array}{l}\text { Shear strength, cure } \\
\text { cycle } 121^{\circ} \mathrm{C} / 60 \mathrm{~min}\end{array}$ & $\begin{array}{l}\text { Average shear force - } \\
\text { shear strength test, } \\
\text { cure cycle } 121^{\circ} \mathrm{C} / 105 \mathrm{~min}\end{array}$ & $\begin{array}{l}\text { Shear strength, cure } \\
\text { cycle } 121^{\circ} \mathrm{C} / 105 \mathrm{~min}\end{array}$ \\
\hline $4056 \mathrm{~N}$ & $14.11 \mathrm{MPa}$ & $4007 \mathrm{~N}$ & $13.21 \mathrm{MPa}$ \\
\hline
\end{tabular}

Based on the observation of the specimens after the tests, it can be concluded that a small area of the sample, at the edges of the bonded layer, was dis-bonded from the metal surface while the area in the middle of the bonded layer showed de-cohesion (the adhesive film can be seen on both parts of the sample) (Fig. 5, 6). 


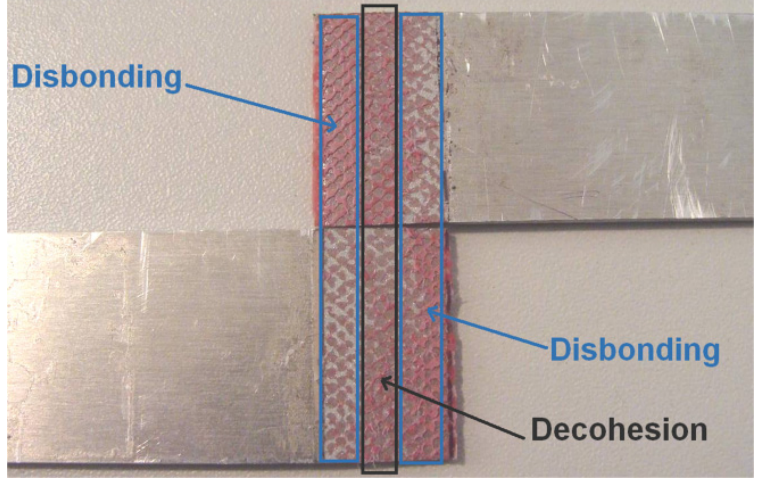

Fig. 5. Specimen after shear strength test, cure cycle $121^{\circ} \mathrm{C} / 60 \mathrm{~min}$

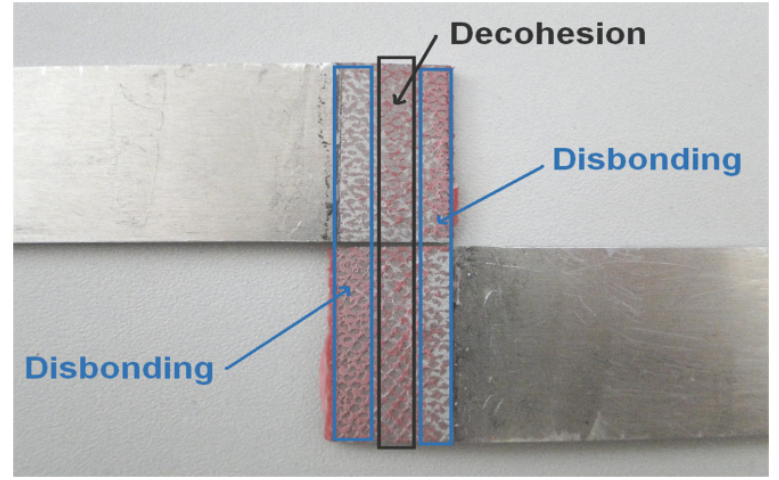

Fig. 6. Specimen after shear strength test, cure cycle $121^{\circ} \mathrm{C} / 105 \mathrm{~min}$

\section{CONCLUSIONS}

The presented research showed that:

- Due to applied force de-cohesive damage of the bonding layer occurred - the surface had been well prepared, since there was no detachment from the metal surface but breaking of the bonding layer;

- Separating force values for specimens made with the use two different cure cycles (according to the data sheet and prolonged) were similar;

- $\quad$ Prolonged cure cycle ensured higher homogeneity and lower porosity of the bonded layer;

- The cure cycle time had little influence on shear strength and values of separating force, hence the adhesive film cure cycle may be extended and adapted to the prepreg cure cycle so that the cure cycles of prepreg and of the adhesive film can be carried out in one operation. This allows for performing damage repair using the Composite Path Bonded Repair method.

\section{REFERENECES}

[1] Heatcon Abaris Training (2008). Advanced Composite Structures: Fabrication and Damage Repair Phase I, Training Materials, Cwmbram, UK.

[2] Heatcon Abaris Training (2008). Advanced Composite Structures: Fabrication and Damage Repair phase II, III, Training Materials, Cwmbram, UK.

[3] „BR 127 Corrosion Inhibiting Primer”, Cytec Engineered Materials, 1996.

[4] „Scotch-Weld Structural Adhesive Film AF 163-2”, 3M, 2002.

[5] ASTM D3762-03 „Standard Test Method for Adhesive-Bonded Surface Durability of Aluminum (Wedge Test)"

[6] Raport z badań „Raport z określenia siły rozdzielającej połączenie klejone...”, Laboratorium Badań Wytrzymałościowych Materiałów ITWL, nr 8a/11, 2011 (in Polish)

[7] Raport z badań „Raport z określenia siły rozdzielającej połączenie klejone...”, Laboratorium Badań Wytrzymałościowych Materiałów ITWL, 8b/11, 2011 (in Polish)

[8] Raport z badań „Raport z określania siły ścinającej...”, Laboratorium Badań Wytrzymałościowych Materiałów ITWL, 7a/11, 2011 (in Polish)

[9] Raport z badań „Raport z określania siły ścinającej...”, Laboratorium Badań Wytrzymałościowych Materiałów ITWL, 7b/11, 2011 (in Polish) 